\title{
Bone and Subcutaneous Fat Influence on Yield, Physicochemical Traits, and Color Stability of Dry-Aged Loin From Grass-Fed Nellore Bulls
}

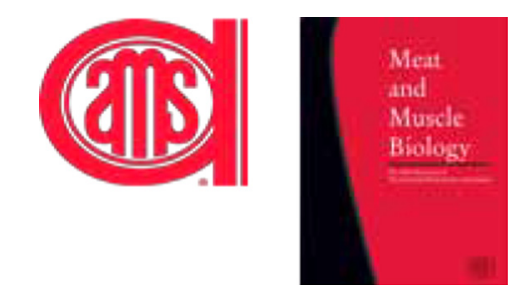

\author{
Ana Paula da Silva Bernardo ${ }^{1}$, Felipe A. Ribeiro ${ }^{2}$, Chris R. Calkins ${ }^{2}$, and Sérgio Bertelli Pflanzer ${ }^{1 *}$ \\ ${ }^{1}$ Department of Food Technology, University of Campinas (Unicamp), Rua Monteiro Lobato, 80, 13083-862, \\ Campinas, São Paulo, Brazil \\ ${ }^{2}$ Department of Animal Science, University of Nebraska, Lincoln, Lincoln, NE 68583-0908, USA \\ *Corresponding author. Email: spflanzer@gmail.com (Sérgio Bertelli Pflanzer)
}

\begin{abstract}
The objective of the current study was to evaluate the influence of bone and subcutaneous fat on yield, physicochemical traits, and color stability of dry-aged beef from grass-fed Nellore bulls. Paired bone-in loins (from the 10th thoracic vertebra to 6th lumbar vertebra) from 8 carcasses were collected and cut in half, and the sections from each carcass were assigned to 4 treatments $(n=8)$ : bone-in with subcutaneous fat, bone-in without subcutaneous fat, boneless with subcutaneous fat, and boneless without subcutaneous fat. Loin sections were dry-aged for $21 \mathrm{~d}$, at $2^{\circ} \mathrm{C}$ and $70 \%$ relative humidity. After dry aging, the half-loins were weighed, trimmed, and weighed again to determine the evaporation loss, trimming loss, and yield. Additionally, water activity, $\mathrm{pH}$, thiobarbituric acid-reactive substances, moisture content, cooking loss, pressed juice percentage, Warner-Bratzler shear force, and color stability (during $9 \mathrm{~d}$ of display) were analyzed. No interactions $(P>0.05)$ between bone and subcutaneous fat were found for evaporation and trimming loss, yield, and physicochemical traits. The treatments did not affect Warner-Bratzler shear force, pressed juice percentage, thiobarbituric acid-reactive substances, and $\mathrm{pH}$ values $(P>0.05)$. Regarding color stability, there was a bone-by-time interaction $(P<0.05)$ for $a^{*}$ and $b^{*}$ parameters. Boneless treatments showed higher $a^{*}$ and $b^{*}$ values $(P<0.05)$ than bone-in treatments, after 6 and $7 \mathrm{~d}$ of display, respectively. Bone-in treatments and treatments with subcutaneous fat had lower evaporation and trimming loss and higher yield compared to boneless treatments and treatments without subcutaneous fat, respectively $(P<0.05)$. Therefore, although bone-in treatments showed lower color stability, bone and subcutaneous fat were considered important factors to the dry-aging process, as both resulted in a greater yield over dry-aged product that had bone and/or fat removed, without compromising other physicochemical traits of dry-aged beef from grass-fed Nellore bulls.
\end{abstract}

Key words: dry-aged beef, bone-in, boneless, subcutaneous fat, yield

Meat and Muscle Biology 4(1): 31, 1-8 (2020)

doi:10.22175/mmb.11141

Submitted 21 April 2020

Accepted 17 July 2020

\section{Introduction}

Brazil is a major exporter and the second largest producer of beef in the world, with 2.2 million metric tons (carcass weight equivalent) exported and 10.2 million tons (carcass weight equivalent) produced in 2019 (USDA, 2019a). The Brazilian cattle herd has about 214 million head (MAPA, 2019). Approximately $80 \%$ of the Brazilian herd consists of Bos taurus indicus cattle (Ferraz and Felício, 2010; Aroeira et al.,
2016), of which $90 \%$ belongs to the Nellore breed (Aroeira et al., 2016). In addition, most Brazilian beef cattle are grass fed (Lobato et al., 2014), and only 10\% are feedlot finished (USDA, 2019b). Compared to grain-fed cattle, beef of grass-fed cattle has less marbling and thinner subcutaneous fat (Maughan et al., 2012). Additionally, the influence of Bos taurus indicus genes affects beef tenderness due to features like muscle structure, physiology, and enzymatic activity (Lawrie, 2005; Lobato et al., 2014). 
Tenderness is the most important sensorial attribute for beef consumption (Morgan et al., 1991; Koohmaraie, 1996; Enfalt et al., 1997; Koohmaraie et al., 2002; Platter et al., 2003; Koohmaraie and Geesink, 2006) and could be improved by aging. Meat is aged by wet-aging (vacuum packaged) or dry-aging (without packaging) processes. Savell (2008) defined dry aging as a process of storing unpackaged carcasses, primals, and/or subprimals, at refrigeration temperatures for 1 to $5 \mathrm{wk}$, allowing enzymatic and biochemical processes to improve tenderness and develop the unique "dry-aged beef" flavor.

Compared to wet aging, dry aging is more expensive (Miller et al., 1985; Smith et al., 2008; DeGeer et al., 2009), and during the dry-aging process, beef loses weight due to moisture evaporation from the lean. Producing dry-aged beef requires strict control of cooling conditions and larger spaces in chambers (Smith et al., 2014). Also, the dry-aging process has significant costs related to weight loss and required trimming due to its dried surface (Kim et al., 2017).

It is well known that the lean tissue expresses greater evaporation loss compared to fat tissue (Johnson et al., 1988). During carcass chilling, subcutaneous fat reduces carcass shrinkage and prevents evaporation from lean meat (Savell et al., 2005). According to Pascoal et al. (2011), the thicker the subcutaneous fat, the lower the carcass weight loss during chilling. However, it is still unclear the amount of evaporation from the lean that the presence of bone and subcutaneous fat prevents during dry aging. In addition, some studies showed that bone-in beef had less weight loss during dry aging compared to boneless beef (Laster et al., 2008; DeGeer et al., 2009; Lepper-Blilie et al., 2016).

Most beef produced in Brazil is from grass-fed Nellore cattle with thin subcutaneous fat; therefore, knowledge of the impact of both subcutaneous fat and bone on dry-aged beef is important to increase yield and achieve a consistent and less costly product. In this sense, to evaluate the feasibility of dry-aged beef produced from grass-fed Nellore bulls, this work assessed the combined effects of bone (bone-in and boneless) and subcutaneous fat (with or without fat) on yield and physicochemical traits of dry-aged beef from grass-fed Nellore bulls.

\section{Materials and Methods}

\section{Samples preparation and treatments}

Paired bone-in loins (from the 10th thoracic vertebra to 6th lumbar vertebra) from 8 grass-fed Nellore bulls (approximately 30 mo old; on average $290 \pm$ $36 \mathrm{~kg}$ of carcass weight; $6.0 \pm 0.4 \mathrm{~mm}$ of fat thickness, measured at the 9 th/10th rib interface at three-fourths of the length of the ribeye from its chine-bone end; marbling score: traces) were collected at a commercial beef plant at $2 \mathrm{~d}$ postmortem. The loins were packed in plastic bags (not vacuumed or sealed), placed in a portable cooler with ice, and transported to the meat lab at the University of Campinas.

At the laboratory, each pair of bone-in loins was cut in half, providing 4 half-loin sections per carcass ( 2 anterior and 2 posterior sections). Then, the half-loin sections from each carcass were balance assigned into the 4 treatments in a predetermined design to avoid an effect of anatomical position. The treatments were bone-in with subcutaneous fat, bone-in without subcutaneous fat, boneless with subcutaneous fat, and boneless without subcutaneous fat. The sections assigned to boneless treatments were deboned (bones were weighed), and sections for treatments without subcutaneous fat had the fat removed (fat was not weighed, since the aim was to simulate carcasses with little or no fat), following the natural connective tissue seam.

After fabrication, the loin sections were aged for another $21 \mathrm{~d}$ in an aging chamber (VN50R model, Metalfrio 2010 (C), Brazil) adapted with a humidifier to control the relative humidity of the chamber. The aging condition was $2^{\circ} \mathrm{C}, 70 \% \pm 5 \%$ relative humidity, and $2.5 \mathrm{~m} / \mathrm{s}$ of air speed.

\section{Evaporation loss, trimming loss, yield, and sampling}

For the bone-in treatments, either with or without subcutaneous fat, each loin section was weighed (initial weight) and then dry-aged for $21 \mathrm{~d}$. After aging, the bone-in loin sections were reweighed (post-aging weight), and the evaporation loss was calculated according to following equation: [([initial weight post-aging weight] / initial weight $) \times 100]$. Then, the bone-in loin sections were deboned, and the dried crust was trimmed. Afterward, bone (bone weight), trimmings (trimming weight), and the loin section (final weight) were weighed. The trimming loss was determined by [(trimming weight / initial weight $) \times 100]$. Furthermore, the yield was calculated by [(final weight / initial weight $) \times 100]$.

Similarly, evaporation, trimming loss, and yield of the boneless treatments, either with or without subcutaneous fat, were determined according to the following steps. First, each loin section assigned to the boneless treatment was deboned. Bone (bone weight) 
and loin sections (initial weight) were weighed. Subsequently, the boneless loin sections were dry-aged for $21 \mathrm{~d}$. After aging, boneless loin sections were reweighed (post-aging weight), and the evaporation loss was calculated by [([initial weight - post-aging weight] / initial weight $\times 100$ ]. Then, boneless loin sections were trimmed. The trimmings (trimming weight) and loin sections (final weight) were weighed. The trimming loss was determined by [(trimming weight $/$ initial weight $) \times 100]$. The yield was calculated by [(final weight / [initial weight + weight of bone] $) \times 100$ ].

Following the fabrication process, the loin sections were cut into steaks, without trimming any of the subcutaneous fat. The steaks were sequentially assigned to the analyses, following the respective order (anterior to posterior): $\mathrm{pH}$ and moisture content ( $2.0 \mathrm{~cm}$ thick), thiobarbituric acid-reactive substances (TBARS; $1.0 \mathrm{~cm}$ thick), Warner-Bratzler shear force and pressed juice percentage ( $2.5 \mathrm{~cm}$ thick), and instrumental color (1.5 cm thick).

\section{Water activity and $\mathrm{pH}$}

The water activity $\left(a_{W}\right)$ was measured on the surface of dry-aged samples. A 2-mm-thick sample was cut out from the dried surface of each loin section and placed in a container for $\mathrm{a}_{\mathrm{W}}$ analysis. Then, $\mathrm{a}_{\mathrm{W}}$ was determined using a water activity meter (Decagon, Brazil, Aqualab 4TE). The $\mathrm{pH}$ was determined in non-aged and aged steaks. To determine the $\mathrm{pH}$, the probe (Mettler Toledo, Brazil, MP125 $\mathrm{pH}$ meter) was first calibrated with buffer solutions of 4.01 and $7.00 \mathrm{pH}$, at $5^{\circ} \mathrm{C}$. Then, the $\mathrm{pH}$ probe previously calibrated was introduced directly into each steak in 2 different positions, measuring the $\mathrm{pH}$ in duplicate.

\section{TBARS and moisture content}

The moisture content was measured in non-aged and aged samples. Each steak assigned to the moisture content analysis had the fat removed, and the internal lean beef was ground. Approximately $10 \mathrm{~g}$ of each ground steak was dried in a forced air convection oven at $105^{\circ} \mathrm{C}$ for $20 \mathrm{~h}$, in triplicate, according to AOAC (1990) procedures. TBARS were measured, prior to color display, on samples of lean beef after aging, in quadruplicate, following Bruna et al. (2001) methodology modified by changing the $15 \mathrm{~mL}$ of $0.38 \mathrm{M} \mathrm{HClO}_{4}$ for $20 \mathrm{~mL}$ of $5 \%$ trichloroacetic acid.

\section{Cooking loss, pressed juice percentage, and Warner-Bratzler shear force}

The pressed juice percentage and Warner-Bratzler shear force were both analyzed using the same steaks. Immediately after aging and fabrication, the steaks were prepared for cooking. Steaks $(2.5 \mathrm{~cm}$ thick $)$ were weighed and cooked in an electric convection oven (Fritomaq, Brazil) at $170^{\circ} \mathrm{C}$, until the internal temperature reached $71^{\circ} \mathrm{C}$. After cooking, the steaks were reweighed to determine the cooking loss.

The pressed juice percentage was determined according to Lucherk et al. (2017) methodology. Immediately after cooking, a slice $(1.00 \mathrm{~cm}$ thick) was cut from the center of each steak. Then, 3 cubes $(1.0 \mathrm{~cm}$ width) were removed from each slice $(1.00 \mathrm{~cm}$ thick). Each cube was weighed between 2 sheets of filter paper (Unifil Filter Paper 501.011, 80 g, $11 \mathrm{~cm}$; Unifil, Brazil) previously stored in a desiccator. Samples were compressed for $30 \mathrm{~s}$ at $78.45 \mathrm{~N}$ using a cylindrical compression probe (model P/36R, Texture Technologies Corp./Stable Micro Systems, UK) coupled to a texture analyzer (model TA-XT Plus; Texture Technologies Corp./Stable Micro Systems, UK). After compression, the sample was removed from the filter paper and the filter paper was reweighed. The results were expressed as the percentage of fluid loss during compression, according to the following equation: (fluid released during compression / cube weight) $\times 100$.

After cutting the samples for the pressed juice percentage method, the samples were saved at room temperature for approximately $30 \mathrm{~min}$ to cool and then they were overwrapped in polyvinyl chloride film and kept at $4{ }^{\circ} \mathrm{C}$ overnight before proceeding with the WarnerBratzler shear force method, following the American Meat Science Association (2015) cookery guidelines. Shear force was determined using 6 round cores $(1.27 \mathrm{~cm}$ diameter), cut following the muscle fibers from each steak using a handheld coring device. Shear force was measured with a texture analyzer (TA-XT Plus, Texture Technologies Corp./Stable Micro Systems, UK) by shearing each core in the center, using a Warner-Bratzler blade attached to the Texture Analyzer. A crosshead speed of $250 \mathrm{~mm} / \mathrm{min}$ was used (American Meat Science Association, 2015).

\section{Color stability during storage}

Color stability during storage was evaluated using a colorimeter (CM 508-d, Hunter MiniScan TMXE, Hunter Associates Laboratory, Inc., Reston, VA). Each steak assigned to color display was placed in 
a polystyrene tray, then wrapped with a polyvinyl chloride film and kept in a refrigerator at $4{ }^{\circ} \mathrm{C}$, with no lights, for $9 \mathrm{~d}$. Color was determined every day following the American Meat Science Association (2012) protocol. The color was evaluated using a colorimeter attached to a moisture protector accessory and previously calibrated using white and black tile standards. The color was measured in 3 different positions of the steak surface (triplicate) by Commission Internationale de I'Eclairage (CIE; "International Commission on Illumination") $L^{*}, a^{*}$, and $b^{*}$ values using the standard observer of $10^{\circ}$, illuminant D65 source and aperture size $25 \mathrm{~mm}$.

\section{Data analyses}

Sixteen bone-in loins, from 8 beef carcasses, were used in this experiment. The bone-in loins were cut in half and then balanced across to the treatments ( 8 halfloins per treatment, $n=8$ ). The experimental design was a $2 \times 2$ factorial with 2 bone effects (bone-in and boneless) and 2 subcutaneous fat effects (with and without fat). The data obtained were statistically analyzed using Statistica version 10.0 (StatSoft, 2010; StatSoft, Hamburg, Germany) by two-way analysis of variance, using the GLM procedure. The degrees of freedom were calculated by KenwardRoger approximation $(\mathrm{DDFM}=\mathrm{KR} 2)$. Data from the color analysis were analyzed by SAS version 9.2 (SAS Institute Inc., Cary, North Carolina). The PROC GLIMMIX procedure was used with bone, fat, and time as a fixed factor and carcasses as a random factor. When significance $(P<0.05)$ was indicated by analysis of variance, the LSMEANS and DIFF functions were used to separate the least-squares means.

\section{Results and Discussion}

\section{Evaporation loss, trimming loss, and yield}

No interactions $(P>0.05$; Table 1$)$ between bone and subcutaneous fat were found for evaporation, trimming loss, and yield.
Boneless samples showed higher evaporation and trimming loss and consequently lower yield compared to bone-in samples $(P<0.05$; Table 1$)$. As expected, bone had a protective effect over the lean tissue, reducing losses in the dry-aging process and increasing yield. Other studies also reported higher evaporation and trimming loss for boneless compared to bone-in dryaged beef (Lepper-Blilie et al., 2016; DeGeer et al., 2009). Similarly, samples without subcutaneous fat had higher evaporation and trimming loss and lower yield compared to samples with subcutaneous fat $(P<0.05$; Table 1$)$. These results indicate that subcutaneous fat also protects the lean tissue, reducing moisture evaporation and increasing dry-aging yield. Although the literature does not report the effects of subcutaneous fat on dry-aged beef, it is known that subcutaneous fat acts as a barrier during carcass chilling, reducing carcass shrinkage and evaporation loss from lean tissue (Savell et al., 2005; Smith and Carpenter, 1973).

Thus, bone and subcutaneous fat were considered important factors during the dry-aging process, reducing evaporation and trimming loss and increasing yield.

\section{$p H, a_{w}$ moisture content, and TBARS}

No interactions $(P>0.05$; Table 2$)$ between bone and subcutaneous fat were found for the $\mathrm{pH}$, surface $a_{w}$, moisture content, and TBARS.

The presence or absence of bone did not affect the $\mathrm{pH}$ or TBARS values $(P>0.05$; Table 2$)$. Boneless samples had lower values of moisture and surface $\mathrm{a}_{\mathrm{W}}$ than bone-in samples $(P<0.05$; Table 2$)$. These results were expected as boneless loins had more exposed muscle surface, which increased evaporation from the lean. Thus, bone influenced only traits related to water content and had no impact on the pH and lipid oxidation. DeGeer et al. (2009) reported similar results in an assessment of bone-in and boneless loin-cut, dry-aged for 21 and $28 \mathrm{~d}$ at $50 \%$ relative humidity. The authors found no differences in

Table 1. Effects (mean \pm SEM) of bone (bone-in and boneless treatments) and subcutaneous fat (with and without subcutaneous fat treatments) on evaporation loss, trimming loss, and yield $(n=32)$

\begin{tabular}{|c|c|c|c|c|c|c|c|}
\hline \multirow[b]{3}{*}{ Trait } & \multicolumn{4}{|c|}{ Treatments } & \multicolumn{3}{|c|}{$P$ Value } \\
\hline & \multicolumn{2}{|c|}{ Bone } & \multicolumn{2}{|c|}{ Subcutaneous Fat } & \multirow[b]{2}{*}{ Bone } & \multirow[b]{2}{*}{ Fat } & \multirow[b]{2}{*}{ Bone $\times$ Fat } \\
\hline & Bone-in & Boneless & With & Without & & & \\
\hline Evaporation Loss, \% & $15.63 \pm 0.76$ & $22.76 \pm 0.96$ & $16.58 \pm 0.88$ & $21.81 \pm 1.23$ & $<0.0001$ & $<0.0001$ & 0.249 \\
\hline Trimming Loss, \% & $8.16 \pm 0.55$ & $18.18 \pm 0.65$ & $11.70 \pm 1.21$ & $14.64 \pm 1.53$ & $<0.0001$ & $<0.0001$ & 0.127 \\
\hline Yield, \% & $49.77 \pm 1.15$ & $40.79 \pm 1.42$ & $48.92 \pm 1.46$ & $41.64 \pm 1.46$ & $<0.0001$ & $<0.0001$ & 0.749 \\
\hline
\end{tabular}


Table 2. Effects (mean \pm SEM) of bone (bone-in and boneless treatments) and subcutaneous fat (with and without subcutaneous fat treatments) on $\mathrm{pH}, \mathrm{TBARS}$, moisture content, surface $\mathrm{a}_{\mathrm{W}}$, cooking loss, pressed juice percentage, and WBSF $(n=32)$

\begin{tabular}{|c|c|c|c|c|c|c|c|}
\hline \multirow[b]{3}{*}{ Trait } & \multicolumn{4}{|c|}{ Treatments } & \multicolumn{3}{|c|}{$P$ Value } \\
\hline & \multicolumn{2}{|c|}{ Bone } & \multicolumn{2}{|c|}{ Subcutaneous Fat } & \multirow[b]{2}{*}{ Bone } & \multirow[b]{2}{*}{ Fat } & \multirow[b]{2}{*}{ Bone $\times$ Fat } \\
\hline & Bone-in & Boneless & With & Without & & & \\
\hline pH & $5.44 \pm 0.01$ & $5.45 \pm 0.01$ & $5.46 \pm 0.01$ & $5.43 \pm 0.01$ & 0.326 & 0.069 & 0.912 \\
\hline TBARS, mg MDA/kg & $0.19 \pm 0.02$ & $0.20 \pm 0.02$ & $0.21 \pm 0.02$ & $0.19 \pm 0.02$ & 0.691 & 0.588 & 0.325 \\
\hline Moisture Content, \% & $74.06 \pm 0.23$ & $72.97 \pm 0.21$ & $73.63 \pm 0.26$ & $73.40 \pm 0.26$ & $<0.05$ & 0.469 & 0.091 \\
\hline Surface $\mathbf{a}_{\mathbf{w}}$ & $0.9409 \pm 0.0020$ & $0.9324 \pm 0.0021$ & $0.9396 \pm 0.0020$ & $0.9336 \pm 0.0024$ & $<0.05$ & $<0.05$ & 0.177 \\
\hline Cooking Loss, \% & $16.66 \pm 0.58$ & $14.06 \pm 0.56$ & $16.49 \pm 0.39$ & $14.23 \pm 0.74$ & $<0.05$ & $<0.05$ & 0.322 \\
\hline Pressed Juice, \% & $33.19 \pm 0.67$ & $32.67 \pm 0.87$ & $33.06 \pm 0.72$ & $32.79 \pm 0.83$ & 0.645 & 0.811 & 0.292 \\
\hline WBSF, $\mathbf{N}$ & $36.03 \pm 1.98$ & $36.46 \pm 3.08$ & $37.97 \pm 3.14$ & $34.52 \pm 1.78$ & 0.905 & 0.342 & 0.113 \\
\hline
\end{tabular}

$\mathrm{a}_{\mathrm{W}}$, water activity; MDA, malondialdehyde; TBARS, thiobarbituric acid-reactive substances; WBSF, Warner-Bratzler shear force.

the $\mathrm{pH}$ and TBARS values between bone-in and boneless samples; however, they found lower moisture content for boneless compared to bone-in samples.
Subcutaneous fat had no effect on the $\mathrm{pH}$, TBARS, or moisture content values $(P>0.05$; Table 2). Samples without subcutaneous fat showed lower surface $a_{W}$ values than samples with subcutaneous fat

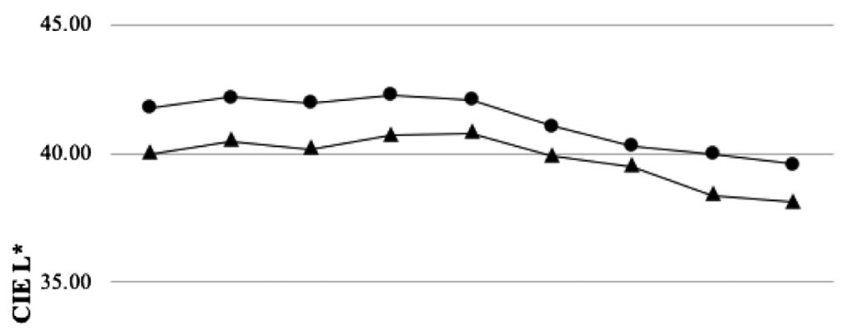

30.00

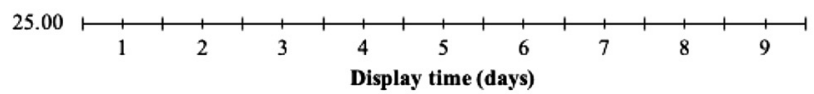

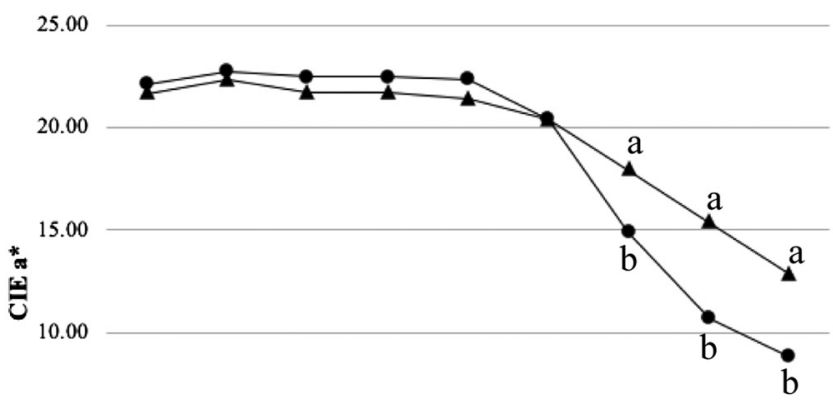

5.00

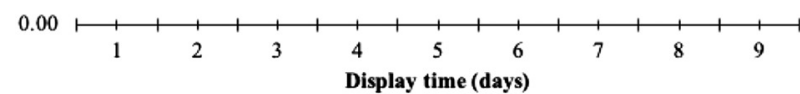

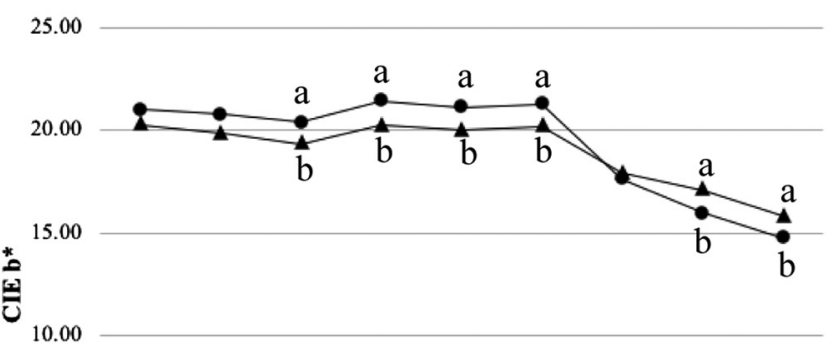

5.00

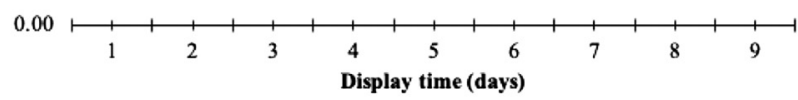

Figure 1. Effects of bone and time interaction on CIE $L^{*}, \mathrm{CIE} a^{*}$, and CIE $b^{*}$ color parameters during $9 \mathrm{~d}$ of display. Standard error: 1.073 (CIE $L^{*}$ ), 0.588 (CIE $\left.a^{*}\right)$, and 0.331 (CIE $\left.b^{*}\right)$. "a" and "b" letters between bone-in and boneless treatments within each day of display are significantly different $(P<0.05)$. (—) Bone-in treatments; (—) Boneless treatments. CIE, Commission Internationale de 1'Eclairage (CIE; "International Commission on Illumination"). 
$(P<0.05$; Table 2$)$, which suggested that the removal of subcutaneous fat increased evaporation from the lean, resulting in higher surface dehydration.

\section{Cooking loss, pressed juice percentage, and Warner-Bratzler shear force}

No interactions $(P>0.05$; Table 2$)$ between bone and subcutaneous fat were found for cooking loss, WBSF, and pressed juice percentage.

Bone-in samples had higher cooking loss values compared to boneless $(P<0.05$; Table 2$)$, attributed to higher moisture content in bone-in samples. The WBSF and pressed juice percentage were not affected by bone-in and boneless treatments $(P>0.05$; Table 2$)$. Other studies also indicated no differences of WBSF values in bone-in and boneless samples (DeGeer et al., 2009; Lepper-Blilie et al., 2016). Similarly, samples with subcutaneous fat showed higher cooking loss than those without subcutaneous fat $(P<0.05$; Table 2), and no differences were observed in WBSF and pressed juice percentage values $(P>0.05$; Table 2).
Regardless of the presence of bone and subcutaneous fat, the treatments were considered very tender, as the WBSF values were lower than $38.2 \mathrm{~N}$ (ASTM, 2011). Furthermore, after cooking, all treatments had similar levels of pressed juice percentage.

\section{Color stability during storage}

No interaction $(P>0.05)$ between bone, fat, and time were found for $L^{*}$ values (lightness), and no differences were observed between the treatments $(P>0.05)$. However, there was a time effect $(P<0.05)$ for $L^{*}$, reducing values from 40.92 to 38.86 (standard error: 0.536; data not shown in tabular form), comparing the first to the last day of display, respectively.

Additionally, there was a bone-by-time interaction $(P<0.05$; Figure 1$)$ for $a^{*}$ (redness) and $b^{*}$ (yellowness) parameters. Both bone-in and boneless treatments showed a decrease in $a^{*}$ values during display. However, after $6 \mathrm{~d}$ of display, bone-in treatments had a greater decrease in $a^{*}$ values compared to boneless $(P<0.05$; Figure 1$)$. Decrease in $a^{*}$ values indicated discoloration during display (Hui et al., 2005;
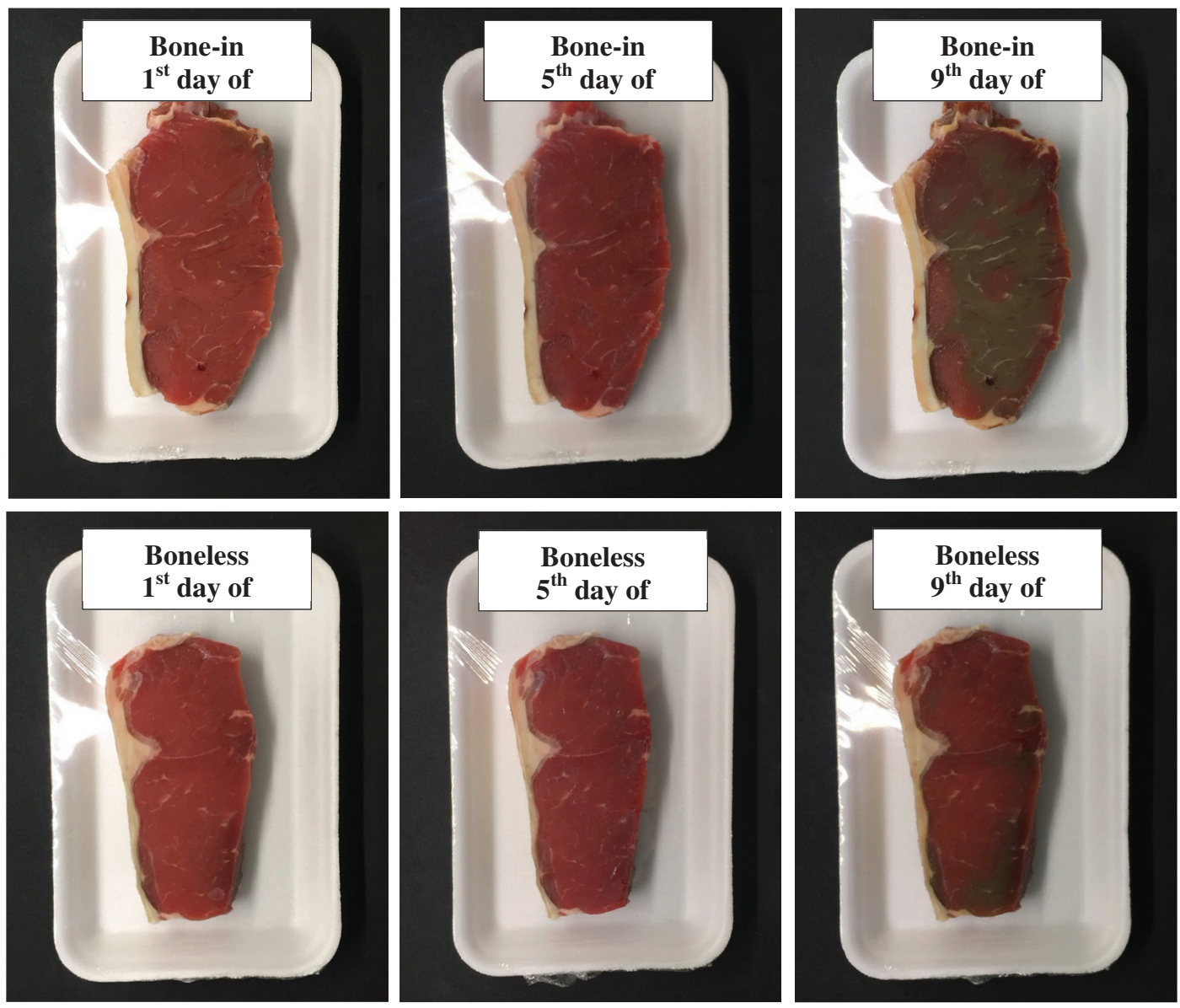

Figure 2. Pictures illustrating the development of color discoloration on bone-in and boneless steaks during display. 
Kim et al., 2017). The $b^{*}$ values were higher for bonein treatments from the third to the sixth day of display compared to boneless $(P<0.05$; Figure 1$)$. No difference was found on the seventh day of display $(P>0.05$; Figure 1), and after $8 \mathrm{~d}$ of display, boneless showed higher $b^{*}$ values than bone-in treatments $(P<0.05$; Figure 1). Thus, the results of instrumental color suggested that boneless treatments had slight, but significant, greater color stability than bone-in (Figure 2), as boneless showed higher $a^{*}$ and $b^{*}$ values after 6 and $7 \mathrm{~d}$ of display, respectively.

Meat discoloration is influenced by many biochemical mechanisms, including metmyoglobin reducing ability and oxygen consumption (English et al., 2016). Both mechanisms are controlled by enzyme activity, and the concentration of enzymes and coenzymes, such as nicotinamide adenine dinucleotide, could change meat color stability. Therefore, further studies are suggested to evaluate these biochemical and enzymatic mechanisms on color stability during the dry-aging process.

In this study, the steaks assigned for the color analysis were refrigerated at $4^{\circ} \mathrm{C}$ without light exposure. In a supermarket display, discoloration could occur faster, due to the temperature fluctuations and light exposure. Lower temperature could increase display color life; however, retail display temperature is frequently up to $7^{\circ} \mathrm{C}$ (Hui et al., 2005). Furthermore, exposure to light promotes the formation of metmyoglobin through photochemical autoxidation (Hui et al., 2005).

\section{Conclusions}

The data from the current study indicate that dryaged beef from grass-fed Nellore bulls resulted in a very tender product. However, further sensory studies should be performed to investigate consumers' acceptance of dry-aged beef from grass-fed Nellore bulls in the Brazilian market. Furthermore, the results show that both bone and subcutaneous fat had a similar protective effect on lean beef, reducing evaporation loss and increasing yield of dry-aged beef. Therefore, considering these results and taking into account that dryaged beef is an expensive product mainly due to the weight lost during its production, the use of bone-in loins with thicker subcutaneous fat to produce dry-aged beef is highly recommended.

\section{Acknowledgments}

The authors have no conflict of interest to declare. The current research was funded by the São Paulo
Research Foundation (FAPESP - Project: 2016/ 02853-9) and financed in part by the Coordination of Superior Level Staff Improvement (CAPES Financial Code 001). The authors would like to thank the National Council for Scientific and Technological Development (CNPq) for providing scholarship support

\section{Literature Cited}

American Meat Science Association. 2012. Meat color measurement guidelines. 2nd ed. Am. Meat Sci. Assoc., Chicago, IL.

American Meat Science Association. 2015. Research guidelines for cookery, sensory evaluation, and instrumental tenderness measurements of meat. 2nd ed. Am. Meat Sci. Assoc., Chicago, IL.

AOAC. 1990. AOAC official methods of analysis. 15th ed. AOAC, Washington, D.C. p. 99-101.

Aroeira, C. N., R. A. Torres Filho, P. R. Fontes, L. A. M. Gomide, A. L. S. Ramos, M. M. Ladeira, and E. M. Ramos. 2016. Freezing, thawing and aging effects on beef tenderness from Bos indicus and Bos taurus cattle. Meat Sci. 116:118-125. https://doi.org/10.1016/j.meatsci.2016.02.006.

ASTM. 2011. ASTM F 2925-11 Standard specification for tenderness marketing claims associated with meat cuts derived from beef. ASTM, Int., West Conshohocken, PA. https://www. astm.org/.

Bruna, J. M., J.A. Ordóñez, M. Fernández, B. Herranz, and L. De La Hoz. 2001. Microbial and physico-chemical changes during the ripening of dry fermented sausages superficially inoculated with or having added an intracellular cell-free extract of Penicillium aurantiogriseum. Meat Sci. 59:87-96. https:// doi.org/10.1016/S0309-1740(01)00057-2.

DeGeer, S. L., M. C. Hunt, C. L. Bratcher, B. A. Crozier-Dodson, D. E. Johnson, and J. F. Stika. 2009. Effects of dry aging of bone-in and boneless strip loins using two aging processes for two aging times. Meat Sci. 83:768-774. https://doi.org/10. 1016/j.meatsci.2009.08.017.

Enfalt, A.C., K. Lundstrom, I. Hansson, N. Lundeheim, P. E. Nystorm. 1997. Effects of outdoor rearing and sire breed (Duroc or Yorkshire) on carcass composition and sensory and technological meat quality. Meat Sci. 45:1-15. https:// doi.org/10.1016/S0309-1740(96)00101-5.

English, A. R., K. M. Wills, B. N. Harsh, G. G. Mafi, D. L. VanOverbeke, and R. Ramanathan. 2016. Effects of aging on the fundamental color chemistry of dark-cutting beef. J. Anim. Sci. 94:4040-4048. https://doi.org/10.2527/jas.20160561 .

Ferraz, J. B. S., and P. E. Felício. 2010. Production systems- An example from Brazil. Meat Sci. 84:238-243. https://doi.org/ 10.1016/j.meatsci.2009.06.006.

Hui, Y. H., W. K. Nip, R. W. Rogers, and O. A. Young. 2005. Meat science and applications. In: O. A. Young, and J. West, editors, Meat color. Marcel Dekker Inc., New York. p. 39-66.

Johnson, R. D., M. C. Hunt, D. M. Allen, C. L. Kastner, R. J. Danler, and C. C. Schrock. 1988. Moisture uptake during 
washing and spray chilling of Holstein and beef-type steer carcasses. J. Anim. Sci. 66:2180-2084. https://doi.org/10.2527/ jas1988.6692180x.

Kim, Y. H. B., B. Meyers, H. W. Kim, A. M. Liceaga, and R. P. Lemenager. 2017. Effects of stepwise dry/wet-aging and freezing on meat quality of beef loins. Meat Sci. 123:5763. https://doi.org/10.1016/j.meatsci.2016.09.002.

Koohmaraie, M. 1996. Biochemical factors regulating the toughening and tenderization processes of meat. Meat Sci. 43:93-201. https://doi.org/10.1016/0309-1740(96)00065-4.

Koohmaraie, M., and G. H. Geesink. 2006. Contribution of postmortem muscle biochemistry to the delivery of consistent meat quality with particular focus on the calpain system. Meat Sci. 74:34-43. https://doi.org/10.1016/j.meatsci.2006. 04.025

Koohmaraie, M., M. P. Kent, S. D. Shackelford, E. Veiseth, T. L. Wheeler. 2002. Meat tenderness and muscle growth: Is there any relationship? Meat Sci. 62:345-352. https://doi.org/10. 1016/S0309-1740(02)00127-4.

Laster, M. A., R. D. Smith, K. L. Nicholson, J. D. W. Nicholson, R. K. Miller, D. B. Griffin, K. B. Harris, and J. W. Savell. 2008. Dry versus wet aging of beef: Retail cutting yields and consumer sensory attribute evaluations of steaks from ribeyes, strip loins, and top sirloins from two quality grade groups. Meat Sci. 80:795-804. https://doi.org/10.1016/j.meatsci. 2008.03.024.

Lawrie, R. A. 2005. Ciência da carne: Constituição química e bioquímica do músculo. Porto Alegre: Artimed. p. 79-120.

Lepper-Blilie, A. N., E. P. Berg, D. S. Buchanan, and P. T. Berg. 2016. Effects of post-mortem aging time and type of aging on palatability of low marbled beef loins. Meat Sci. 112:63-68. https://doi.org/10.1016/j.meatsci.2015.10.017.

Lobato, J. F. P., A. K. Freitas, T. Devincenzi, L. L. Cardoso, J. U. Tarouco, R. M. Vieira, D. R. Dillenburg, and I. Castro. 2014. Brazilian beef produced on pastures: Sustainable and healthy. Meat Sci. 98:336-345. https://doi.org/10.1016/j.meatsci. 2014.06.022.

Lucherk, L. W., T. G. O’Quinn, J. F. Legako, R. J. Rathmann, J. C. Brooks, and M. F. Miller. 2017. Assessment of objective measures of beef steak juiciness and their relationships to sensory panel juiciness ratings. J. Anim. Sci. 95:2421-2437. https:// doi.org/10.2527/jas2016.0930.

MAPA. 2019. Projeções do agronegócio: Brasil 2018/19 a 2028/29. Ministério da Agricultura, Pecuária e Abastecimento, Brasília, DF.

Maughan, C., R. Tansawat, D. Cornforth, R. Ward, and S. Martini. 2012. Development of a beef flavor lexicon and its application to compare the flavor profile and consumer acceptance of rib steaks from grass- or grain-fed cattle. Meat Sci. 90:116-121. https://doi.org/10.1016/j.meatsci.2011.06.006.
Miller, M. F., G. W. Davis, and C. B. Ramsey. 1985. Effect of subprimal fabrication and packaging methods on palatability and retail caselife of loin steaks from lean beef. J. Food Sci. 50:1544-1546. https://doi.org/10.1111/j.1365-2621.1985. tb10529.x.

Morgan, J. B., J. W. Savell, D. S. Hale, R. K. Miller, D. B. Griffin, H. R. Cross, and S. D. Shackelford. 1991. National beef tenderness survey. J. Anim. Sci. 69:3274-3283. https://doi.org/ $10.2527 / 1991.6983274 x$.

Pascoal, L. L., J. F. P. Lobato, J. Restle, F. N. Vaz, R. Z. Vaz, and P. S. Pacheco. 2011. Carcass boneless yield of Braford steers, classified according to fat coverage class. Rev. Bras. Zootecn. 40:1388-1395. https://doi.org/10.1590/S151635982011000600030 .

Platter, W. J., J. D. Tatum, K. E. Belk, P. L. Chapman, J. A. Scanga, and G. C. Smith. 2003. Relationships of consumer sensory ratings, marbling scores, and shear force value to consumer acceptance of beef strip loin steaks. J. Anim. Sci. 81:27412750. https://doi.org/10.2527/2003.81112741x.

Savell, J. W. 2008. Dry-aging of beef, executive summary. National Cattlemen's Beef Association. https://www.beefresearch.org/ CMDocs/BeefResearch/Dry\%20Aging\%20of\%20Beef.pdf. (Accessed September 9, 2020).

Savell, J. W., S. L. Mueller, and B. E. Baird. 2005. The chilling of carcasses. Meat Sci. 70:449-459. https://doi.org/10.1016/j. meatsci.2004.06.027.

Smith, G. C., and Z. L. Carpenter. 1973. Postmortem shrinkage of lamb carcasses. J. Anim. Sci. 36:862-867. https://doi.org/10. 2527/jas1973.365862x.

Smith, A. M., K. B. Harris, D. B. Griffin, R. K. Miller, C. R. Kerth, and J. W. Savell. 2014. Retail yields and palatability evaluations of individual muscles from wet-aged and dry-aged beef ribeyes and top sirloin butts that were merchandised innovatively. Meat Sci. 97:21-26. https://doi.org/10.1016/j.meatsci. 2013.12.013.

Smith, R. D., K. L. Nicholson, J. D. W. Nicholson, K. B. Harris, R. K. Miller, D. B. Griffin, and J. W. Savell. 2008. Dry versus wet aging of beef: Retail cutting yields and consumer palatability evaluations of steaks from US Choice and US Select short loins. Meat Sci. 79:631-639. https://doi.org/10.1016/j. meatsci.2007.10.028.

USDA. 2019a. Livestock and poultry: World markets and trade. United States Department of Agriculture, Foreign Agricultural Service, Washington, DC.

USDA. 2019b. Brazil: Livestock and Products Annual - 2019 Annual Livestock Report. Global Agricultural Information Network (GAIN) Report Number BR1924. United States Department of Agriculture, Foreign Agricultural Service, Washington, DC. 